a syrinx extending from the second and fourth cervical to the eighth thoracic segments and it may be presumed that this is involving the descending autonomic pathways. The intermedio-lateral columns or autonomic outflow paths in the spinal cord may also be affected, in which case the absence of Horner's syndrome and the preservation of the inspiratory vaso-constrictor reflex implies that this lesion is incomplete.

\section{Acknowledgments}

We wish to thank Professor R. W. Gilliatt for permission to publish this report, and for his advice and encouragement in its preparation. We are grateful also to the Department of Radiology at the Middlesex Hospital for performing the micturating cine-cystogram on this patient.

\section{References}

Bannister, R., Ardill, L. \& Fentem, P. (1967) Defective autonomic control of blood vessels in idiopathic orthostatic hypotension. Brain, 90, 725.

Barany, F.R. \& CoOPER, E.H. (1956) Pilomotor and sudomotor innervations in diabetes. Clinical Science, 15, 533.

BATES, C.P. (1971) Hunterian Lecture. Annals of the Royal College of Surgeons of England (in press).
BerLiner, K. (1940) Use of alpha lobeline for measurement of velocity of blood flow. Archives of Internal Medicine, 65, 896.

Bradbury, S. \& Eggleston, C. (1925) Postural hypotension: A report of three cases. American Heart Journal, 1, 73.

Coon, J.M. \& Rothman, S. (1941) Sweat response to drugs with nicotine-like action. Journal of Pharmacology and Experimental Therapeutics, 73, 1.

Ellis, L.B. \& HAynes, F.W. (1936) Postural hypotension with particular reference to its occurrence in disease of the central nervous system. Archives of Internal Medicine, 58, 773.

GARDNER, W.J. (1965) Hydrodynamic mechanism of syringomyelia; its relationship to myelocoele. Journal of Neurology, Neurosurgery and Psychiatry, 28, 247.

Gilliat,, R.W., GuttmanN, L. \& Whitteridge, D. (1948)

Inspiratory vaso-constriction in patients after spinal injuries. Journal of Physiology, 107, 67.

Gross, M. (1970) The effects of posture on subjects with cerebro-vascular disease. Quarterly Journal of Medicine, $39,485$.

GutTManN, L. (1940) Topographic studies of disturbances of sweat secretion after complete lesions of peripheral nerves. Journal of Neurology and Psychiatry, 3, 197.

JANOWITZ, H.D. \& Grossman, M.I. (1950) The response of the sweat glands to some locally acting agents in human subjects. Journal of Investigative Dermatology, 14, 453.

SHARPEY-SCHAFER, E.P. (1953) Effects of coughing on intrathoracic pressure, arterial pressure and peripheral blood flow. Journal of Physiology, 122, 351.

\title{
Addison's disease, vitiligo and multiple autoantibodies
}

\author{
C. J. BuRns-COX \\ M.B., M.R.C.P.
}

\author{
J. E. G. PeArson \\ D.M., F.R.C.P.
}

\section{Bristol General Hospital, Bristol}

'IN some cases the discoloration occurs in patches, or perhaps certain parts are so much darker than others as to impart to the surface a mottled or somewhat chequered appearance; and in one instance there were in the midst of this dark mottling, certain insular portions of the integument presenting a blanched or morbidly white appearance, either in consequence of these portions having remained altogether unaffected by the disease . . . or, as I believe, from an actual defect of colouring matter in parts.' Thomas Addison's description of a patient with vitiligo in his first series of patients with disease of the adrenal gland (1855).

Recently evidence has accumulated that vitiligo often accompanies autoimmune responses. The patient described below had vitiligo, alopecia areata, Addison's disease of the adrenals and thyrotoxicosis-all diseases associated with the presence of autoantibodies.

\section{Case report}

In 195\% a married English housewife aged 29 was seen because of increasing weight loss, weakness and craving for salt for 1 year with amenorrhoea for 3 months. Previously, she had noticed bald patches on her scalp which had completely disappeared without treatment.

She had not been seriously ill before and had married 5 years previously but not become pregnant. Her father had died of rheumatic heart disease and pulmonary tuberculosis, her mother had been thyrotoxic but was well as were two siblings. She appeared thin and wasted and her blood pressure was $95 / 70 \mathrm{mmHg}$. There was brown pigmentation of the buccal mucosa and exposed areas of her skin but there were white patches over the knuckles. There was no poliosis or premature greying of the hair.

Haemoglobin $11.3 \mathrm{~g} / 100 \mathrm{ml}$, ESR $48 \mathrm{~mm} / \mathrm{hr}$, plasma $\mathrm{Na}^{+} 133, \mathrm{~K}^{+} 6 \cdot 1$ and $\mathrm{Cl}^{-} 100.5 \mathrm{mEq} / \mathrm{l}$. 
Urinary 17-ketosteroids $3.7 \mathrm{mg}$ and 17 -ketogenic steroids $6.1 \mathrm{mg} / 24 \mathrm{hr}$ (Norymberski). X-ray chest showed a very small heart and minimal bilateral apical fibrosis with overlying pleural thickening. $\mathrm{X}$-ray abdomen showed calcification in pelvic glands but not in the region of the adrenals.

She was started on cortisone $12.5 \mathrm{mg}$ t.d.s. daily with 9-alpha-fluorocortisone $0.05 \mathrm{mg}$ on alternate days and her symptoms at once disappeared completely.

Four years later she became depressed and lost weight and her menses stopped. She had little cough or sputum and sputum microscopy and culture were negative for tubercle bacilli. ESR $36 \mathrm{~mm} / \mathrm{hr}$, X-ray chest showed bilateral hilar gland enlargement and an area of soft infiltration in the right upper zone $2 \mathrm{~cm}$ in diameter. Her Mantoux test was weakly positive with $30 \mathrm{TU}$.

She was given streptomycin, PAS and INAH but developed a high fever, rash and hypotension. Drug desensitization was achieved under increased cortisone cover and treatment continued for 2 years with $\mathrm{X}$-ray and clinical improvement. The hilar gland enlargement showed regression within 2 months.

In 1965 she developed herpes zoster on the right flank which healed normally. A year later she attended complaining of a goitre and on examination had signs of thyrotoxicosis. ${ }^{131}$ I uptake tests confirmed the diagnosis of hyperthyroidism, (4-hr thyroid uptake $52 \%$, and $48-\mathrm{hr} \mathrm{PBl}$ as $\%$ dose/1 $0.36 \%$ ). TRC test for thyroglobulin antibody was positive only at $1 / 25$. Serum gamma-globulin level was raised at $1.7 \mathrm{~g} / 100 \mathrm{ml}$ and immuno-electrophoresis showed a raised IgA of $540 \mathrm{mg} / 100 \mathrm{ml}$ with normal IgG and IgM levels. Rheumatoid latex test positive.

Her cortisone was increased and the hyperthyroidism settled with carbimazole.

Since then she has felt well and her goitre has diminished in size. Her worry is now the embarrassment of increasing vitiligo over the hands, wrists, arms, neck and face. The Addisonian pigment is still prominent and accentuates the pallor of the depigmented areas.

In June 1970 her serum was examined for the presence of autoantibodies:

Thyroid antibodies: thyroglobulin TRC, 1/20; colloid immunofluorescent antibodies, ++ ; cytoplasmic antibodies CFT, 1/32; cytoplasmic immunofluorescent antibodies, ++ .

Gastric parietal cell antibodies: immunofluorescent, ++ ; CFT, ++ .

Intrinsic factor antibodies, positive. Adrenal antibodies cytoplasmic fluorescence, weak positive. Non-organ specific ANF, negative. A recent serum vitamin $B_{12}$ level was $300 \mathrm{pg} / \mathrm{ml}$.

\section{Discussion}

Many workers have shown that a patient with one autoantibody-associated disease is likely to have many different autoantibodies. The association of vitiligo with other diseases in which autoantibodies are present is so strong that vitiligo must be considered an autoimmune disease (Dawber, 1970).

In 1955, Allison \& Curtis showed a substantial association between pernicious anaemia and vitiligo. Of 531 patients with vitiligo, twenty-two or $4.1 \%$ had pernicious anaemia. The incidence of vitiligo in a Caucasian population is about $1 \%$.

Cunliffe et al. (1968) demonstrated thyroid antibodies to be present more commonly in patients with vitiligo than controls, and Dawber (1968) found the same for patients with diabetes mellitus.

Bor, Feiwal \& Chanarin (1969) showed an increase in parietal cell antibodies in patients with vitiligo. These were present in $22.5 \%$ of sixty-two patients compared with $8 \%$ of controls.

Brostoff, Bor \& Feiwal (1969) reported that $4 \%$ of eighty patients with vitiligo had organ-specific antibodies to adrenal tissue compared with less than $1 \%$ of controls.

Another abnormality associated with vitiligo is Sutton's halo naevus. This consists of an area ofo depigmentation surrounding a cellular naevuse which histologically shows a dense lymphocytico infiltration with progressive destruction of the naevus. Fluorescent antibody tests have failed to show any IgG fixed to naevus cells (Kopf, 1969) and histologically vitiligo does not show any similar lymphocytic infiltration.

A further point of interest is the retrospective possibility that our patient's changing $\mathrm{X}$-rays in 1963 represented sarcoidosis. Karlish \& MacGregor (1970) have described ten patients with sarcoidosis who developed thyroid disorders within 18 months of the onset; six of them had hyperthyroidism of which two showed sarcoid granulomas in the thyroid histologically. Four other patients later had Hashimoto's thyroiditis with thyroid antibodies. Their eleventh case showed thyroiditis, myxoedema and adrenal failure with thyroid, adrenal and gastric antibodies in the serum.

They suggest that sarcoid inflammation may trigger off immunity to affect one or more endocrine glands leading to their fibrosis and failure.

\section{Acknowledgment}

We would like to thank Professor D. Doniach for carrying out antibody estimations.

\section{References}

ADDison, T. (1855) On the Constitutional and Local Effects of Diseases of the Suprarenal Capsules. Highley, London.

Allison, J.R. \& CURTIS, J.C. (1955) Vitiligo and pernicious anaemia. Archives of Dermatology, 72, 407. 
Bor, S., Feiwal, M. \& Chanarin, I (1969) Vitiligo and its aetiological relationship to organ-specific auto-immune disease. British Journal of Dermatology, 81, 83.

Brostoff, J., Bor, S. \& Feiwal, M. (1969) Auto-antibodies in patients with vitiligo. Lancet, ii, 177.

Cunliffe, W.J., Hall, R., Newall, D.J. \& Stevenson, G.J. (1968) Vitiligo, thyroid disease and auto-immunity. British Journal of Dermatology, 80, 135.
DAWBER, R.P.R. (1968) Vitiligo in mature-onset diabetes mellitus. British Journal of Dermatology, 80, 275.

DAWBER, R.P.R. (1970) Late onset vitiligo associated with auto-immune disease. Postgraduate Medical Journal, 46, 276.

Karlish, A.J. \& MaCGregor, G.A. (1970) Sarcoidosis, thyroiditis and Addison's disease. Lancet, ii, 330.

Kopf, A.W. (1969) Discussion on multiple halo naevi. Archives of Dermatology, 99, 187.

Postgraduate Medical Journal (February 1972) 48, 117-118.

\title{
Haemangioma of the bladder
}

\author{
A. Morales* \\ M.D. \\ Department of Urology, Queen's University, Kingston, Ontario
}

VASCULAR tumours of the bladder are rare. Less than fifty cases have been reported in the literature at the time of writing, and few of these have been documented histologically (Fuleihan \& Cordonnier, 1969). In this paper a case of cavernous haemangioma of the bladder is presented together with the histological features and results of surgical treatment.

\section{Case report}

A 15-year-old boy was referred to hospital with a history of intermittent attacks of gross haematuria since the age of 2 years. The haematuria appeared to be related to physical exertion and, as he grew older, he was able to state that each episode was associated with diffuse back pain. He had been treated successfully in the past by bed rest alone, the haematuria usually stopping within a few days. However, in view of the persisting nature of his symptoms, he was admitted to hospital for further investigation. He admitted no other urological symptoms and his general health was good.

On examination, he was a well-developed Caucasian boy, slightly pale and in no distress. BP $120 / 70 \mathrm{mmHg}$ and the pulse $78 / \mathrm{min}$. The haemoglobin was $10 \cdot 2 \mathrm{~g} / 100 \mathrm{ml}$ with a haematocrit of $34 \%$. The urine contained albumin and, on microscopy, two or three red blood cells were seen per high power field. Coagulation studies were normal. The only abnormality seen on the excretory urogram was a filling defect on the right lateral wall of the bladder (Fig. 1). At cystoscopy, a large $(2 \times 3 \mathrm{~cm})$ bluish-red sessile mass was noted in the right postero-lateral wall of the bladder. There were four similar tumours of less than $0.5 \mathrm{~cm}$ in diameter located at the dome. A biopsy of the larger mass was taken and was reported to be 'cystitis with numerous blood vessels'. Three days after cystoscopy, an exploration of the

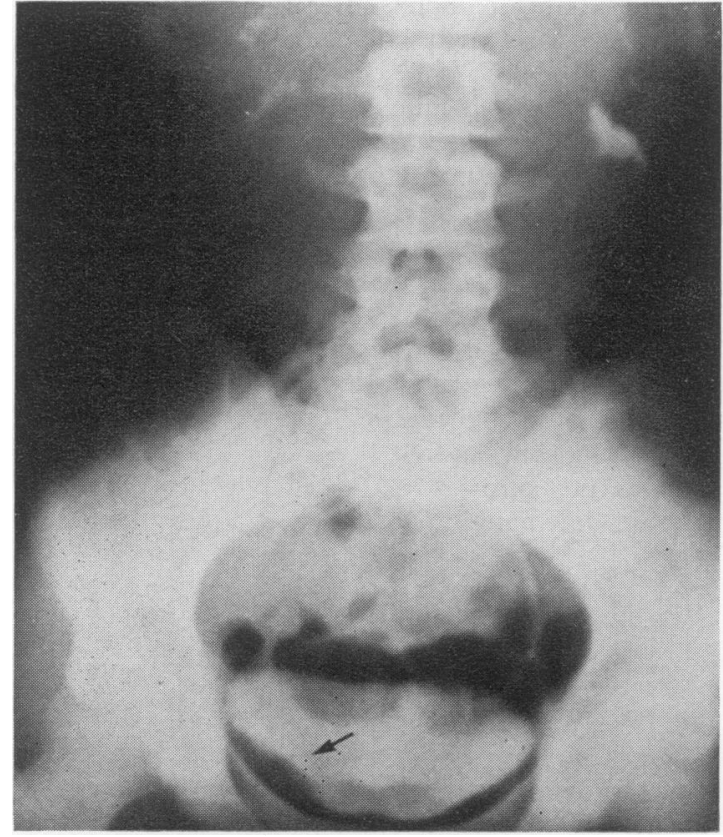

Fig. 1. Intravenous pyelogram. Arrow shows a filling defect on the right lateral wall of the bladder.

bladder was carried out because of severe, persisting haematuria which was found to be originating from the biopsy site. The large tumour was removed by segmental cystectomy and the smaller lesions were fulgurated. The patient made an uneventful recovery, and on removal of the urethral catheter, the urine

* Present address: Department of Urology, Royal Infirmary, Aberdeen. 